\title{
Estimating functional efficiency in energy futures markets
}

\author{
Javier García-Verdugo• Meliyara Consuegra* \\ Department of Applied Economics, UNED, Spain
}

Received: 5 September 2013

Revised: 28 October 2013

Accepted: 29 October 2013

\begin{abstract}
This paper proposes a method to estimate the functional efficiency of energy futures markets in terms of social welfare. Using a standard futures markets structural model, it can be concluded that the error committed when using futures prices at moment $t$ to predict spot prices at $t+1$ results in welfare losses through resource misallocation. Therefore, the social welfare associated with the presence of energy futures markets can be measured using a social loss (SL) statistic and its components. This statistic is computed for six energy futures contracts with eight maturities each with data from April 1992 to December 2012. The results confirm the consistency and robustness of the method. Finally, several practical uses for the SL statistic are suggested.
\end{abstract}

Keywords: futures energy markets, futures prices, spot prices, social welfare, social loss, functional efficiency

JEL Classification Codes: A11, C53, D61, D70, D81

\section{Introduction}

Throughout the past decades energy futures markets have received increasing attention from researchers. One of the most promising areas of research focuses on the informative efficiency of petroleum futures markets, considered as a fundamental factor in the functional efficiency of these markets. Several authors, such as Crowder and Hamed (1993), Peroni and McNow (1998), Gulen (1998), Switzer and El-Khoury (2007), Maslyuk and Smyth (2009), and Kawamoto and Hamori (2011), find evidence confirming that crude oil futures markets are efficient ${ }^{1}$, although the results about bias are not as conclusive. The paper by Kawamoto and Hamori (2011) is closest to our approach in the sense that they also used a sample of futures contracts with different maturities. Their results showed that the WTI crude oil futures market was consistently efficient within the 8-month maturity level, but was only consistently

\footnotetext{
*Corresponding author. E-mail: meliyara@bec.uned.es.

Citation: García-Verdugo, J. and Consuegra, M. (2013) Estimating functional efficiency in energy futures markets, Economics and Business Letters, 2(3), 105-115.

1 "Efficient" in this context refers to the weak form of the efficient market hypothesis, which assumes that the information of all past prices is reflected in today's prices (Kawamoto and Hamori, 2011).
} 
efficient and unbiased within the 2-month level. The only exception to the conclusions supporting crude oil futures efficiency is a recent research by Stevens (2013) in which the WTI futures market is shown to be inefficient according to the weighted least squares (WLS) and the trimmed least squares (TLS) tests, but efficient when the ordinary least squares (OLS) test is used.

However, the tests carried out in the literature are only able to produce dichotomic results on the existence of efficiency and are limited to examining the efficiency of crude oil. Unlike these authors, this paper uses a generic structural model of futures markets in which efficiency is measured with an indicator that evaluates the functional efficiency of energy futures markets in terms of social welfare. Based on the concept of social surplus, our model tries to show that the error committed when using futures prices to estimate spot prices in the future translates into a loss in welfare due to the erroneous allocation of resources.

The term "functional efficiency" refers to the efficiency with which futures markets perform the functions of price risk transfer and price discovery. Regarding the transfer of price risks, participants seek to protect themselves from the variability of prices, and the efficiency of the hedging instrument depends on the relative variation between futures contract prices and the prices in the physical market. Price discovery refers to the fact that each participant in the futures markets acts using all available information and their own estimates about future price changes. In this paper the functional efficiency of energy futures markets is assessed estimating the social loss derived from allocation errors that are committed when the prices of futures contracts are used as estimators for prices in the physical markets.

The rest of the paper is organised as follows: the second section presents the basic model; the third section develops the theoretical and empirical indicators for the quantification of social welfare loss in futures markets; the fourth explains the characteristics of the data used for the empirical analysis; in the fifth section the empirical results are presented, and the concluding remarks follow.

\section{The basic model: Supply, demand and equilibrium in futures contract markets}

The basic lines of the model used in this paper were developed by Stein (1986). This model was also used by Brooks (1989), Stein (1991), Hong (1989), Pindick and Rotemberg (1988), Avsar and Goss (2002), and Pennings and Garcia (2010). Different versions of this model have been used by Kawai (1983), Turnovsky (1983), Bond (1984), and Chari and Jagannathan (1990). Stein's model is based on the optimization of individual decisions made by different market participants and has several useful features. First, it theoretically explains which variables determine equilibrium prices, equilibrium open interest and the variability of prices. Second, it can incorporate exogenous and endogenous expectations, as well as participants with different forecasting abilities. Above all, it can be used to analyse the ex-post contribution of futures markets to social welfare through the optimal inter-temporal allocation of resources, which is the main reason why it was selected to be used in this paper.

Stein's model only has two periods. In period t producers make their production decisions, both producers and consumers decide the proportion of their commercial positions to be hedged with futures, and speculators decide the volume of their investment. In period $t+1$ exchanges are made in the physical market and open positions in the futures markets are cancelled.

In general, it can be stated that commercial participants are attracted to energy futures markets by the possibility of protecting themselves from price risks. On the other hand, the variability of these same prices attracts speculators and determines their corresponding level 
of expected benefits. As a result of the participants' hedging or speculative decisions, an optimal level of production and an optimal position in the futures market is obtained.

The literature on commodities futures markets traditionally assumes that speculative transactions result in net long speculative positions. Accordingly, the only commercial participants included in Stein's model are assumed to hold a net short position in energy futures contracts, i.e. they are sellers hedging against the risk of falling prices. In the model, futures prices determine production, while consumption exogenously equals production.

The equilibrium of the futures market gives a first expression for $q_{t+1}(t)$, the price in $t$ of a futures contract maturing in $t+1$ :

$$
q_{t+1}(t)=(1-\delta) E_{m} p(t+1 ; t)
$$

$E_{m} p$ is the subjective expectation of the prices expected in $t$ for period $t+1$ by commercial participants and speculators, and $\delta$ is a parameter that reflects the sufficiency or insufficiency of speculation to attend the need for commercial hedging or hedging pressure. At the same time, if the quality of the hedging instrument is assumed to be perfect ${ }^{2}$, the equilibrium of the goods market determines that:

$$
q_{t+1}(t)=c S(t+1)
$$

Equation (2) is the market supply function since $c S(t+1)$ is the aggregate marginal production cost when marginal costs of individual commercial participants are assumed to be linear and $c$ is the slope of the individual supply functions of the commercial participants. Using (1) the supply could be written in terms of the subjective expectation of the participants in the market about the spot price of the commodity:

$$
O \equiv E_{m} p(t+1 ; t)=\frac{c}{1-\delta} S(t+1)
$$

On the other hand, since consumption exogenously equals production in the model, the market demand function can be given as:

$$
D(t+1) \equiv p^{*}(t+1)=u^{*}(t+1)-b S(t+1)
$$

where $\mathrm{b}$ is the slope of the individual demand functions of the commercial participants. Considering that $u^{*}(t+1)$ is a random parameter relevant to the second period, demand $D(t+1)$ follows an unknown probability distribution and $p^{*}(t+1)$ is the random spot price in $t+1$. $E D(t+1)$ is the objective expectation of demand, and its expression is:

$$
E D(t+1) \equiv E p(t+1)=E u(t+1)-b S(t+1)
$$

$E p(t+1)$ is the expected value of the spot price. The difference between the value $\mathrm{D}$ and its objective expectation ED is known as the inevitable error $\varepsilon(t+1)$. This error is due to the unpredictable variation of the random parameter $\mathrm{u}^{*}$ around its expected value $E u(t+1)$. This difference can be shown to be equal to $\varepsilon(t+1)=p(t+1)-E p(t+1)$, and is represented in Figure 1 by the segment $\mathrm{CB}^{3}$.

\footnotetext{
${ }^{2}$ The quality of the hedging instrument is measured as the correlation coefficient between the price of the underlying commodity of the futures contract and the price of the actual product relevant to the hedgers. The quality of the hedging instrument is perfect when $r^{2}=1$.

${ }^{3}$ Since the error is inevitable, $\mathrm{E}[\varepsilon(t+1)]=0$.
} 
Figure 1. Social loss associated with the suboptimal allocation of resources

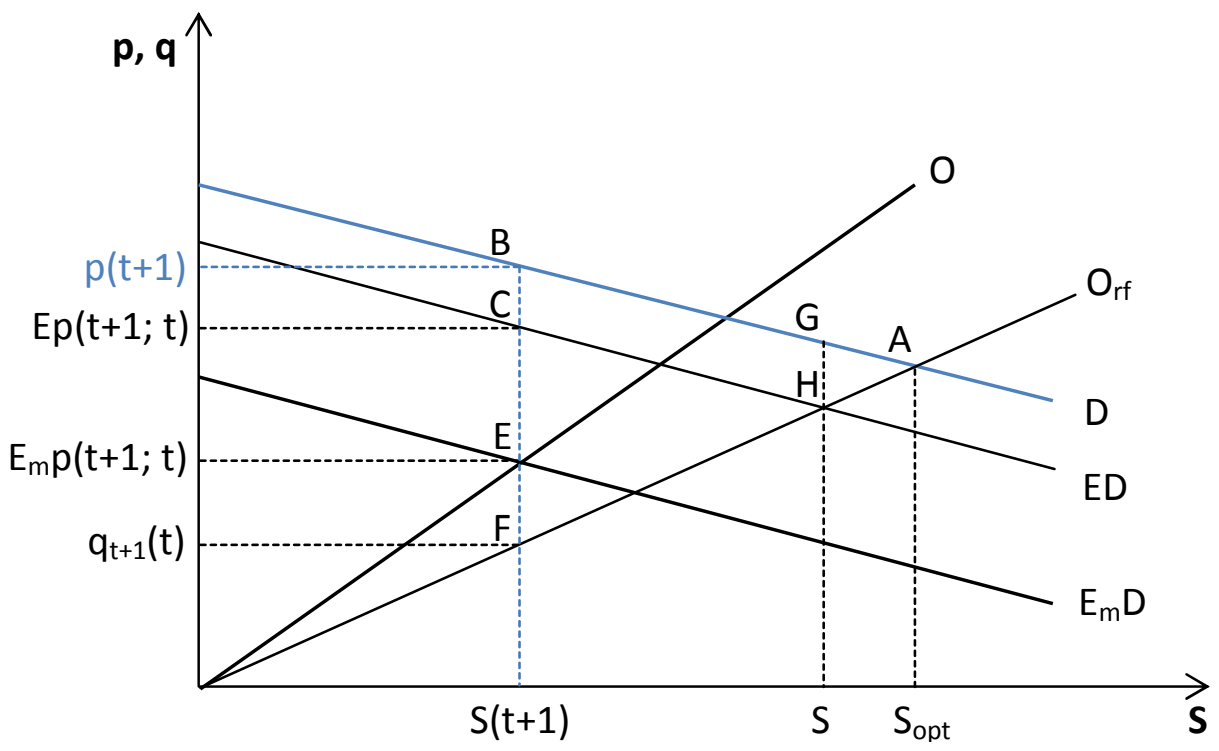

Lacking the capacity for perfect forecast, companies can only attempt to predict the value of the objective expectation of demand ED. Their actual estimation of ED is known as the subjective expectation of demand $E_{m} D$.

$$
E_{m} D(t+1) \equiv E_{m} p(t+1)=E_{m} u(t+1)-b S(t+1)
$$

The difference between both expectations of the demand function is known as the Bayesian error $y_{m}(t)$, represented in Figure 1 as the segment EC. It can be shown that $y_{m}(t)=E p(t+1)-E_{m} p(t+1 ; t)$. For convenience, Figure 1 represents $\mathrm{D}>\mathrm{ED}>\mathrm{E}_{\mathrm{m}} \mathrm{D}$, but it need not be so.

The intersection of the supply curve with $E_{m} D$ determines the subjective expectation of the equilibrium price and the amount to be produced in $t$. In turn, $E_{m} p(t+1 ; t)$ and the risk premium determines the futures price $q_{t+1}(t)$, as is shown in equation (1). Eventually, the production $S(t+1)$ reaches the market in $t+1$ and is faced with the actual demand curve $\mathrm{D}$, which results in $p(t+1)$.

The consideration or not of a risk premium (embodied in the parameter $\delta$ ) affects the futures price because it shifts the supply function, as can be seen from equation (3): the actual supply curve $O$ in Figure 1 shifts to the left of the risk-free supply function $O_{\text {rf }}$ because a positive risk premium is assumed. Therefore the distance between these two curves (EF in Figure 1) represents the risk premium, given by $E_{m} p-q_{t+1}(t)$, that can be considered the third source of forecast error.

Let us take a step back to put these concepts in perspective. Stein (1981) identified two types of social loss in the forward markets: the avoidable and the unavoidable. The unavoidable error represents the difference between the market equilibrium price and the expected equilibrium price. The avoidable error is the gap between the expected equilibrium price and the forward price. This model was expanded by Stein (1986) for futures markets. He identified three types of errors: the inevitable error, the Bayesian error and the risk premium. For futures markets the unavoidable error is called inevitable; the Bayesian error occurs because of the difference between the subjective and objective expected price of the contract; finally, the risk premium occurs when expected demand exceeds marginal cost.

The inevitable and Bayesian errors plus the risk premium comprise the total forecast error: 
$p(t+1)-q_{t+1}(t)=[p(t+1)-E p]+\left[E p-E_{m} p\right]+\left[E_{m} p-q_{t+1}(t)\right]$

\section{Social loss in the model}

$S(t+1)$ (see Figure 1) is the volume of output that reaches the market at $t+1$, while $S_{\text {opt }}$ is the optimal volume of production, which is obtained from the intersection of $\mathrm{O}_{\mathrm{rf}}$ and actual demand D. Following Stein (1986), we assume that the loss of social welfare —or simply social loss - is the triangular area ABF between the effective demand curve and the marginal cost curve $\left(\mathrm{O}_{\mathrm{rf}}\right)$, between the actual output $S(t+1)$ and the perfect-foresight equilibrium output $S_{\text {opt }}$, while the triangle AGH represents the inevitable social loss caused by the random parameter $u^{*}(t+1)$ included in $\mathrm{D}$ (see equation 4$)$. Therefore, total social loss can be represented with the expression:

$$
L(t+1)=\frac{1}{2}\left[p(t+1)-q_{t+1}(t)\right] \cdot\left[S_{o p t}-S(t+1)\right]
$$

This value is the product of the price forecast error and the deviation of production $S(t+1)$ from the optimal value $S_{\text {opt }}$. Since the production deviation depends on the price deviation ${ }^{4}$, the loss of social welfare can be rewritten as:

$$
L(t+1)=K\left[p(t+1)-q_{t+1}(t)\right]^{2}, \text { with } K=\frac{1}{2(b+c)}
$$

Therefore, ex-post social loss $L(t+1)$ is a multiple $\mathrm{K}$ of the square of the price deviation between the subsequently realized cash price $p(t+1)$ and the futures price.

Stein (1986) defines the social loss statistic SL as the ratio of the social loss $L(t+1)$ to the minimum or inevitable social loss $L_{0}$. Using equation (9), it can be seen that the expected social loss $E[L(t+1)]$ is equal to the constant $K$ times the mean squared error $(M S E)$ of the price forecast for $t+1$. On the other hand, the expectation of the inevitable social loss $E\left(L_{0}\right)=E K[\varepsilon(t+1)]^{2}$ can be written as $K$ times $M S E_{0}$. Therefore, the value of $K$ is not needed to compute the SL statistic for the estimation of social welfare loss:

$$
S L=\frac{E[L(t+1)]}{E\left(L_{0}\right)}=\frac{E K\left[p(t+1)-q_{t+1}(t)\right]^{2}}{E K[\varepsilon(t+1)]^{2}}=\frac{M S E(t+1)}{M S E_{0}}
$$

At the same time that we move from two periods to a more realistic k periods, we define the empirical equivalent of $\operatorname{MSE}(k)$ as:

$$
\operatorname{MSE}(k)=\frac{1}{n} \sum_{t=1}^{n}\left[\ln p(t+k)-\ln q_{t+k}(t)\right]^{2}
$$

where $n$ is the number of observations in the data. $\operatorname{MSE}(k)$ is the mean squared error derived from the estimation of the spot price in period $t+k$ using the price in $t$ of the futures contract which expires $k$ periods later. On the other hand, $M S E(1)$ will be used as an empirical proxy of the unobservable minimum expected social loss $M S E_{0}$. Thus the last term in (10) can be rewritten as:

$$
S L(k)=\frac{M S E(k)}{M S E(1)}
$$

\footnotetext{
${ }^{4}$ According to Stein (1986), $S_{\mathrm{opt}}-S(t+1)=\left[p(t+1)-q_{\mathrm{t}+1}(t)\right] /(\mathrm{b}+\mathrm{c})$, with $b$ and $c$ indicating the slopes of individual demand and supply functions respectively, as indicated before.
} 
In a similar way, the decomposition of the forecast error in (7) contains only theoretical variables that could only be used if observable proxies are found. Fortunately, an alternative method $^{5}$ provides an empirical equivalent for the decomposition of $M S E(k)$ according to the type of error:

$$
\operatorname{MSE}(k)=E\left[p(t+k)-q_{t+1}(t)\right]^{2}=(\bar{p}-\bar{q})^{2}+\left[\sigma_{q}(1-d)\right]^{2}+\left(1-r^{2}\right) \sigma_{p}^{2}
$$

where $\bar{p}$ and $\bar{q}$ are the means of spot and futures prices during the relevant period, $\sigma_{p}^{2}$ is the variance of spot prices, $\sigma_{q}$ is the standard deviation of futures prices, $d$ is the regression coefficient of $p$ over $q$, and $r$ is the correlation coefficient between $p$ and $q$. The first term is the part of $M S E$ which is derived from the difference between the mean values of spot and future prices, the second is due to the risk premium which separates the value of $d$ from the unit, and the third is a composition of the inevitable and Bayesian errors.

Now, the empirical approximation to $S L(k)$ in (12) includes squared terms that exaggerate the absolute differences between the values of the statistic and reduce the informative content of the computed mean of forecast deviations. Following the method applied by Ma (1989) in his efficiency contrasts, the squared root of the mean squared error can be used as an alternative:

so that:

$$
R M S E(k)=\left[\frac{1}{n} \sum_{t=1}^{n}\left[\ln p(t+1)-\ln q_{t+k}(t)\right]^{2}\right]^{\frac{1}{2}}
$$

$$
S L(k)=\frac{R M S E(k)}{R M S E(1)}
$$

\section{Data}

The energy futures contracts selected for the empirical analysis are traded in the Intercontinental Exchange (ICE), at London, and in the Chicago Mercantile Exchange (CME). Six products and eight maturities from each futures contract were selected: crude Brent and diesel from ICE; and WTI (West Texas Intermediate) crude oil, heating oil, gasoline, and natural gas from CME. Our analysis is based on monthly data between April 1992, and December 2012. The analysis was repeated for three sub-periods: 1992-1996, 1997-2006 and 2007-2012. The selection of these three sub-periods was determined by years in which important financial crises took place: 1997 for the South-East Asian crisis, and 2007 for the recent international financial crisis. All of these products have registered a significant trading volume, and the open interest in each contract is higher than those negotiated in other energy futures markets.

Following Kumar's (1991) approach, we used futures prices corresponding to the last trading day of each month during the period of study. Kumar tested the hypothesis that the last futures price of each month contains all relevant information up to that moment, which is why those prices should be more accurate in predicting prices in the future. He concluded that price predictions made during the last trading day were superior to those obtained with alternative methods.

\footnotetext{
${ }^{5}$ Vid. Maddala (1977) and Stein (1986).
} 


\section{Results}

\section{The SL statistic}

It was explained in previous sections that the SL statistic is a way of quantifying the social welfare loss which can be attributed to errors in prediction that agents commit when estimating physical market prices with futures market prices as a reference. As stated earlier, the minimum social loss of using a futures price as an estimator is related to the contract closest to maturity, and this was considered the inevitable social loss. The values computed for the SL statistic are presented in Table 1.

As expected, for every sub-period as well as for the whole period 1992-2012, SL values increase for every product with the distance to contract maturity, showing that futures prices see their capacity for prediction reduced when $k$ increases. However, SL values corresponding to natural gas, heating oil and gasoline increase less markedly with the distance to maturity than those of Brent, WTI and gasoil. More specifically, the SL values of natural gas increase the least (slightly over $61 \%$ for values of $\mathrm{k}$ between 2 and 8 ) and those of gasoil the most (almost $137 \%$ for the same maturities).

Table 1 ranks energy futures according to total SL values for the closest maturity $(\mathrm{k}=2)$. Natural gas and heating oil futures contracts presented the lowest values of the SL statistic (less social welfare loss), while gasoil futures presented the greatest for all maturities. The social welfare loss associated with Brent, gasoline and WTI contracts was significantly greater than that of natural gas or heating oil, but much less than that of gasoil. However, the specific ranking varies somewhat as $k$ increases ${ }^{6}$. Significantly, the futures contracts whose associated SL values increased most with the time to maturity are usually those that fare worse when considering the absolute SL values and vice versa.

Also quite interesting are the results that can be drawn from observing the rate of variation of the SL statistic over time. Between the first and the last sub-periods (1992-1996 and 20072012), heating oil, gasoil, and natural gas futures presented the greatest increases in SL values for every $k$ (on average $32.5 \%, 31.5 \%$ and $30.6 \%$ respectively), while the gasoline market presented a reduction in social loss with an average of $-32.1 \%$. WTI and Brent crudes also showed positive variations for every maturity (15.4\% and $16.4 \%$ respectively on average), around half the increase recorded for heating oil, natural gas and diesel contracts. In summary, during the period 1992-2012 energy futures contracts have generally shown increases in social welfare loss, with the exception of gasoline futures which showed a clear improvement in the behaviour of the SL statistic. These increases or reductions could have multiple causes, such as changes to the features of futures contracts, changes in the international environment of the physical markets, the international financial crisis, etc.

\footnotetext{
${ }^{6}$ The ranking stays as shown in Table 1 for $\mathrm{k}=2$ through 4 , but then changes and stays the same for $\mathrm{k}=5$ through 8. From lower to higher SL values, this second ordering is as follows: natural gas, heating oil, Brent, gasoline, WTI and gasoil.
} 
Table 1. SL (k) values for 1992-2012 and three sub-periods

\begin{tabular}{|c|c|c|c|c|c|c|c|}
\hline SL & $\mathbf{k}=2$ & $\mathbf{k}=\mathbf{3}$ & $k=4$ & $\mathbf{k}=5$ & $k=6$ & $\mathrm{k}=7$ & $k=8$ \\
\hline \multicolumn{8}{|l|}{ Heating oil } \\
\hline Total & 1.19 & 1.42 & 1.63 & 1.84 & 2.03 & 2.17 & 2.31 \\
\hline 1992-1996 & 1.12 & 1.29 & 1.44 & 1.59 & 1.75 & 1.90 & 2.08 \\
\hline $1997-2006$ & 1.14 & 1.30 & 1.38 & 1.44 & 1.48 & 1.50 & 1.52 \\
\hline 2007-2012 & 1.37 & 1.78 & 2.18 & 2.55 & 2.85 & 3.04 & 3.16 \\
\hline \multicolumn{8}{|l|}{ Natural gas } \\
\hline Total & 1.32 & 1.50 & 1.67 & 1.82 & 1.93 & 2.02 & 2.13 \\
\hline 1992-1996 & 1.27 & 1.41 & 1.43 & 1.45 & 1.49 & 1.51 & 1.53 \\
\hline $1997-2006$ & 1.34 & 1.48 & 1.65 & 1.77 & 1.83 & 1.91 & 2.01 \\
\hline 2007-2012 & 1.36 & 1.64 & 1.97 & 2.27 & 2.49 & 2.68 & 2.87 \\
\hline \multicolumn{8}{|c|}{ Brent crude oil } \\
\hline Total & 1.60 & 2.02 & 2.38 & 2.67 & 2.93 & 3.15 & 3.31 \\
\hline 1992-1996 & 1.59 & 2.06 & 2.34 & 2.53 & 2.65 & 2.70 & 2.75 \\
\hline $1997-2006$ & 1.53 & 1.85 & 2.14 & 2.40 & 2.67 & 2.95 & 3.18 \\
\hline 2007-2012 & 1.70 & 2.25 & 2.70 & 3.07 & 3.35 & 3.53 & 3.63 \\
\hline \multicolumn{8}{|c|}{ WTI crude oil } \\
\hline Total & 1.62 & 2.07 & 2.47 & 2.80 & 3.08 & 3.31 & 3.46 \\
\hline 1992-1996 & 1.64 & 2.13 & 2.37 & 2.57 & 2.68 & 2.71 & 2.75 \\
\hline 1997-2006 & 1.58 & 1.94 & 2.25 & 2.54 & 2.85 & 3.16 & 3.41 \\
\hline 2007-2012 & 1.66 & 2.21 & 2.73 & 3.13 & 3.42 & 3.61 & 3.70 \\
\hline \multicolumn{8}{|l|}{ Gasoline } \\
\hline Total & 1.76 & 2.26 & 2.53 & 2.77 & 2.99 & 3.17 & 3.34 \\
\hline 1992-1996 & 1.92 & 2.53 & 2.93 & 3.27 & 3.64 & 3.89 & 4.09 \\
\hline $1997-2006$ & 2.14 & 2.70 & 2.90 & 3.10 & 3.33 & 3.65 & 4.01 \\
\hline $2007-2012$ & 1.52 & 1.97 & 2.29 & 2.55 & 2.74 & 2.83 & 2.87 \\
\hline \multicolumn{8}{|l|}{ Gasoil } \\
\hline Total & 1.87 & 2.46 & 2.98 & 3.41 & 3.82 & 4.15 & 4.43 \\
\hline 1992-1996 & 1.75 & 2.23 & 2.57 & 2.80 & 2.94 & 2.97 & 3.00 \\
\hline 1997-2006 & 1.83 & 2.32 & 2.69 & 3.03 & 3.38 & 3.75 & 4.08 \\
\hline $2007-2012$ & 2.00 & 2.80 & 3.60 & 4.23 & 4.80 & 5.16 & 5.45 \\
\hline
\end{tabular}

Decomposition of the social loss according to type of error

The decomposition of the MSE will be used as a proxy for the decomposition of the SL statistic. As shown in equation (15), the numerator is the square root of $\mathrm{MSE}(\mathrm{k})$ and so the percentage of error decomposition is the same in both cases; besides, the denominator RMSE(1) remains unchanged for all values of $\mathrm{k}$. For this reason the decomposition of the $\operatorname{MSE}(\mathrm{k})$ have been used as the empirical equivalent of the decomposition of SL(k).

Table 2 presents the percentage composition of the MSE error by type of error. It should be remembered that there are three components of the MSE: mean difference (MD), risk premium (RP), and the sum of the inevitable and Bayesian errors (IB). 
Table 2. Decomposition of forecast errors, 1992-2012 (\%)

\begin{tabular}{|c|c|c|c|c|c|c|c|c|}
\hline MSE & $\mathbf{k}=1$ & $\mathbf{k}=\mathbf{2}$ & $\mathbf{k}=\mathbf{3}$ & $k=4$ & $\mathbf{k}=5$ & $\mathrm{k}=6$ & $\mathbf{k}=7$ & $\mathbf{k}=\mathbf{8}$ \\
\hline \multicolumn{9}{|c|}{ Heating oil } \\
\hline MD & 13.0 & 11.7 & 10.2 & 9.7 & 9.5 & 9.6 & 10.0 & 10.4 \\
\hline $\mathrm{RP}$ & 2.3 & 2.1 & 2.2 & 2.3 & 2.4 & 2.6 & 2.8 & 3.0 \\
\hline IB & 84.7 & 86.2 & 87.5 & 88.0 & 88.1 & 87.8 & 87.2 & 86.6 \\
\hline \multicolumn{9}{|c|}{ Natural gas } \\
\hline MD & 3.4 & 2.9 & 2.6 & 2.3 & 2.2 & 2.1 & 1.9 & 1.7 \\
\hline $\mathrm{RP}$ & 6.1 & 9.0 & 11.5 & 13.7 & 15.6 & 16.8 & 17.9 & 18.9 \\
\hline IB & 90.5 & 88.0 & 85.9 & 84.0 & 82.2 & 81.1 & 80.2 & 79.4 \\
\hline \multicolumn{9}{|c|}{ Brent crude oil } \\
\hline MD & 0.1 & 0.7 & 1.4 & 2.0 & 2.7 & 3.4 & 4.2 & 5.1 \\
\hline $\mathrm{RP}$ & 0.9 & 1.3 & 1.8 & 2.2 & 2.4 & 2.8 & 3.0 & 3.2 \\
\hline IB & 99.0 & 98.0 & 96.8 & 95.8 & 94.8 & 93.8 & 92.8 & 91.8 \\
\hline \multicolumn{9}{|c|}{ WTI crude oil } \\
\hline MD & 0.0 & 0.2 & 0.7 & 1.2 & 1.7 & 2.3 & 2.9 & 3.6 \\
\hline $\mathrm{RP}$ & 2.3 & 2.9 & 3.6 & 4.2 & 4.7 & 5.2 & 5.6 & 5.8 \\
\hline IB & 97.7 & 96.9 & 95.7 & 94.6 & 93.6 & 92.5 & 91.5 & 90.6 \\
\hline \multicolumn{9}{|c|}{ Gasoline } \\
\hline $\mathrm{MD}$ & 1.9 & 0.0 & 0.2 & 0.7 & 1.5 & 2.3 & 3.3 & 4.4 \\
\hline $\mathrm{RP}$ & 1.5 & 0.1 & 0.0 & 0.1 & 0.2 & 0.4 & 0.6 & 0.9 \\
\hline IB & 96.6 & 99.9 & 99.8 & 99.2 & 98.3 & 97.3 & 96.1 & 94.8 \\
\hline \multicolumn{9}{|l|}{ Gasoil } \\
\hline MD & 4.4 & 2.9 & 2.8 & 2.9 & 3.2 & 3.5 & 3.9 & 4.5 \\
\hline $\mathrm{RP}$ & 1.2 & 0.8 & 0.9 & 1.1 & 1.2 & 1.5 & 1.8 & 2.1 \\
\hline IB & 94.3 & 96.3 & 96.2 & 96.0 & 95.6 & 95.0 & 94.2 & 93.4 \\
\hline
\end{tabular}

For all maturities most of the error is explained by the IB component. As expected, the results show that the closest a futures contract is to maturity, the greatest part of the total error is caused by the IB component, whereas as $k$ increases, the error explained by MD and/or RP becomes relatively larger. The heating oil presented the greater error due to $\mathrm{MD}$, and then gasoil and natural gas. The natural gas was the contract with the highest content of error caused by RP, accounting for $18.9 \%$ of the error at $k=8$, while the weight of the RP component in the other products did not exceed $5.8 \%$.

\section{Concluding remarks}

This paper has presented a useful and simple measurement of the functional efficiency of futures energy markets. It has been confirmed that the SL statistic is a consistent indicator that can be used to quantitatively estimate social losses associated with the use of energy futures markets for spot price forecasting by using concepts and tools related to social surplus theory. It was found that between 1992 and 2012 heating oil, diesel, and natural gas contracts presented the greatest increases in social loss, while the gasoline market presented a reduction in social loss almost as great as the increase in the other markets. WTI and Brent contracts 
showed less variation of the SL statistic than natural gas and diesel futures. Therefore, the increase in welfare as measured by the reduction of social loss only took place in gasoline futures markets.

The futures contracts whose associated SL values increased most with the time to maturity are usually those that fare worse when considering the absolute SL values and vice versa.

Natural gas and heating oil were the futures contracts which, on average, showed less social loss in terms of welfare, i.e. presented a lower value of the statistic SL. On the other hand, gasoil presented the greatest social loss of all of the products studied.

Regarding the decomposition of the error, for all of the contracts the great majority of the error was caused by inevitable and Bayesian errors. Natural gas is the product with the greatest error content explained by the presence of a risk premium.

Concerning the evolution of functional efficiency over time, during the period 1992-2012 energy futures contracts have generally shown increases in social welfare loss, with the exception of gasoline futures. The general reduction in the ability of energy futures markets to accurately forecast cash prices may have multiple causes, either poorer market performance or greater price volatility for energy products. Up to now no specific studies have been published, but the higher volatility in the physical markets-especially since 2007-seems to be the most probable explanation of the results.

A great deal of exploring is still needed in this area. One way of explaining the evolution of the SL statistic over time would be to analyse the behaviour of the spot markets of energy products, and also the changes in futures markets indicators such as open interest and trading volume. These indicators were only taken into account in this paper as criteria for selecting the contracts to be considered, given that the energy futures that were chosen were those with higher open interest and trade volume. Another way of exploring the quantification of the contribution of futures markets to social welfare could be the comparison between the values of the SL statistic associated with futures markets with the values of the indicator in forward energy markets, as was suggested by Stein (1981). Finally, a natural expansion of this research would be to apply this quantification method to other groups of commodities, such as food and metals.

Acknowledgements. Thanks to Asa Ekengren for his recommendations. We also thank the two anonymous referees for their helpful comments and suggestions.

\section{References}

Avsar, S.G. and Goss, B.A. (2001) Forecast errors and efficiency in the US electricity futures market, Australian Economic Papers, 40(4), 479-499.

Brooks, R.D. (1989) A social loss approach to testing the efficiency of Australian financial futures, Monash University Department of Economics, Working Paper.

Crowder, W.J. and Hamed, A. (1993) A cointegration test for oil futures market efficiency, The Journal of Futures Markets, 13, 933-941.

Gülen, S. (1998) Efficiency in the crude oil futures market, Journal of Energy Finance and Development, 3, 13-21.

Hong, B.G. (1989) Speculation and market performance, $\mathrm{PhD}$ thesis, Brown University.

Kawamoto, K. and Hamori, S. (2011) Market efficiency among futures with different maturities: evidence from the crude oil futures, The Journal of Futures Markets, 31(5), 487-501.

Kumar, M.S. (1991) Forecasting accuracy of crude oil futures prices, International Monetary Fund Working Paper. 
Ma, C.W. (1989) Forecasting efficiency of energy futures prices, Journal of Futures Markets, $5,393-419$.

Maddala, G.S. (1977) Econometrics, McGraw-Hill.

Maslyuk, S. and Smyth, R. (2009) Cointegration between oil spot and futures prices of the same and different grades in the presence of structural change, Energy Policy, 37, 1687-1693.

Pennings, J.M. and Garcia, P. (2010) Risk and hedging behavior: the role and determinants of latent heterogeneity, Journal of Financial Research, 33(4), 373-401.

Peroni, E. and McNown, R. (1998) Noninformative and informative tests of efficiency in three energy futures markets, The Journal of Futures Markets, 18(8), 939-964.

Pindick, R.S. and Rotemberg, J.J. (1988) The excess co-movement of commodity prices, NBER Working Paper Series 2671.

Stein, J. (1991) An evaluation of the performance of speculative markets, in L. Phlips (ed): Commodity Futures and Financial Markets, Kluwer,153-178.

Stein, J. (1961) The simultaneous determination of spot and futures prices, American Economic Review, 51, 1012-1025.

Stein, J. (1979) Spot, forward and futures, in H. Levy (ed): Research in Finance I, JAI Press, Connecticut.

Stein, J. (1981) Speculative price: economic welfare and the idiot of chance, Review of Economics and Statistics, 63(2), 565-583.

Stein, J. (1986) The economics of futures markets, Basil Blackwell.

Stevens, J. (2013) Testing the efficiency of futures market for crude oil using weighted least squares, Applied Economics Letters, 20(18), 1611-1613.

Switzer, L.N. and El-Khoury, M. (2007) Extreme volatility, speculative efficiency, and the hedging effectiveness of the oil futures markets, The Journal of Futures Markets, 27, 61-84. 